\title{
Analysis of Follow-Up Results after Successful Conservative Treatment of Pediatric Appendiceal Abscess- A Single Institutional Retrospective Study
}

\author{
Bao Jingfeng, Zhuang Wenjun, Ding Zhili, Sun Hailiang and Hong Yaqiang* \\ Department of Pediatric Surgery, Affiliated Changzhou Children's Hospital of Nantong University, Changzhou 213000, China
}

\begin{abstract}
Purpose: The follow-up results of successful conservative treatment of appendiceal abscess in children were analyzed to further explore the value of interval appendectomy (IA).

Method: Follow-up was conducted for children with appendiceal abscess who were successfully treated conservatively for the first time in our department from January 2015 to December 2019. The recorded data included: imaging data (abdominal ultrasound or abdominal CT), frequency of recurrence, inflammatory indicators, intraoperative status, postoperative pathology, etc.

Results: A total of 48 children (male/female $=21 / 27$ ), with an average age of 10.82 .6 years, were included in this study. They were followed up to December 31 , 2019, during which four patients underwent interval appendectomy, and the pathology suggested chronic appendicitis or simple appendicitis. There were 9 cases with recurrence (18.7\%), among which 7 cases occurred within 3 months after the first conservative treatment, 4 cases underwent surgery, 5 cases were treated with conservative treatment again, 1 case relapsed and underwent surgical treatment, and the remaining children had not relapsed during follow-up up to date.

Conclusion: The recurrence rate of children with successful conservative treatment of appendiceal abscess is low and there is no significant correlation between appendiceal beecar and recurrence. Planned interval appendectomy is not necessary. If the operation is selected, the interval of at least 10 weeks is recommended.
\end{abstract}

Keywords: Children, Appendiceal abscess, Interval appendectomy

\section{Introduction}

Acute appendicitis is the most common acute abdomen in children. For non-complicated appendicitis, positive surgery after a clear diagnosis has become a consensus. However, there has been controversy over the treatment of complicated appendicitis, especially appendiceal abscess. On this, there are mainly three views: (1) one-stage surgery; (2) conservative treatment; (3) conservative treatment plus planned interval appendectomy. We prefer the second option, here we report the follow-up results of children who have been successfully conservative treated with appendiceal abscess in our hospital since January 2015.

\section{Materials and Methods}

A total of 55 children with appendiceal abscess were admitted to our department from January 2015 to December 2019 and 48 children successfully treated with conservative treatment for the first time were included in this study, including 21 males and $27 \mathrm{females,} \mathrm{with} \mathrm{an} \mathrm{average}$ age of $10.8 \pm 2.6$ years. Criteria for successful conservative treatment of appendicitis abscess: abdominal pain relief, no fever, normal diet, normal urine and feces, white blood cell count, neutrophil classification, c-reactive protein and other indicators returned to normal, imaging examination (abdominal ultrasound or CT) showed abscess absorption or significantly reduced. The study was approved by our ethics committee.

*Correspondence to: Hong Yaqiang, Department of Pediatric Surgery, Affiliated Changzhou Children's Hospital of Nantong University, Changzhou 213000, China, E-mail:1611828234@qq.com

Citation: Jingfeng B, Wenjun Z, Zhili D, Hailiang S, Yaqiang H (2020) Analysis of Follow-Up Results after Successful Conservative Treatment of Pediatric Appendiceal Abscess- A Single Institutional Retrospective Study. J Pediatr Congenit Dis 6(1): 102. DOI: https://doi.org/10.47275/2379-6707-102.

Received: May 26, 2020; Accepted: June 11, 2020; Published: June 16, 2020

Copyright: $\odot 2020$ Jingfeng B, et al. This is an Open Access article distributed under the terms of the Creative Commons Attribution 4.0 International License (CCBY) (http://creativecommons.org/licenses/by/4.0/) which permits commercial use, including reproduction, adaptation, and distribution of the article provided the original author and source are credited. 
Citation: Jingfeng B, Wenjun Z, Zhili D, Hailiang S, Yaqiang H (2020) Analysis of Follow-Up Results after Successful Conservative Treatment of Pediatric Appendiceal Abscess- A Single Institutional Retrospective Study. J Pediatr Congenit Dis 6(1): 102. DOI: https://doi.org/10.47275/2379-6707-102.

By consulting the medical record management system of our hospital, we obtained the clinical data of the children during their treatment in the hospital. Follow-up results were obtained after discharge through outpatient review and telephone inquiry. The main recorded data included: imaging findings (abdominal ultrasound or CT), frequency of recurrence, time interval between recurrence and the end of the first course of treatment, inflammatory indicators, recurrence treatment mode, postoperative pathology, etc.

SPSS19.0 statistical software was used for statistical analysis. Measurement data were normally distributed and expressed as mean \pm standard deviation. The chi-square test was used to compare the counting data rate, and the difference was statistically significant if the $\mathrm{P}$ value was less than 0.05 .

\section{Results}

Forty-eight children met the inclusion criteria, and follow-up time ranged from 0.4 to 5 years. During the mean follow-up (2.1 \pm 1.5$)$ years, 39 children showed no recurrence symptoms such as abdominal pain. At the request of family members, 4 patients underwent interval appendectomy at least 2 months after the end of conservative treatment. Recurrence occurred in 9 cases, except 1 case 20 months after conservative treatment, and the remaining 8 cases all occurred within 4 months after conservative treatment. 4 patients with recurrence underwent emergency surgery.

Among the 5 patients who were treated conservatively again, 1 case relapse and underwent surgical treatment, 1 had interval appendectomy and the remaining 3 had no recurrence during follow-up, as shown in table 1.

All the 4 patients underwent interval appendectomy at least 2 months after successful Conservative treatment and the operation time was within 50 minutes. No obvious adhesion was found during the operation, and the postoperative pathology suggested chronic appendicitis. One of the cases was found to have a distal autotomy with approximately $2 \mathrm{~cm}$ of proximal appendix remaining.

Five patients underwent emergency surgery with recurrence, and the operation time was between 47 and 117 minutes. The operation time was between 47 and 117 minutes. Most of them were found that the appendix adhered to the surrounding area during the operation. The pathology was consistent with acute appendicitis, partly with gangrenous perforation. No significant postoperative complications occurred in the above two groups, as shown in tables 2 and 3.

Among the 48 cases, 22 cases were indicated to have fecalith (abdominal CT showed high density shadow and ultrasound showed strong echogenic mass). During the follow-up period, 5 cases had recurrence, among which 1 case had disappeared before the interval appendectomy.

There were 4 recurrence cases in the 26 coprolite-free group, and the difference in recurrence rate between the two groups was not statistically significant, as shown in table 4 .

\begin{tabular}{|c|c|c|c|c|c|c|c|}
\hline & \multirow{2}{*}{$\begin{array}{c}\text { Age } \\
\text { (Years) }\end{array}$} & \multirow[t]{2}{*}{ Gender } & \multirow{2}{*}{$\begin{array}{c}\text { Recurrence interval } \\
\text { (Mon) }\end{array}$} & \multirow{2}{*}{$\begin{array}{c}\text { Onset time } \\
\text { (h) }\end{array}$} & \multirow[t]{2}{*}{ fecalith } & \multirow{2}{*}{$\begin{array}{c}\text { CRP } \\
(\mathrm{mg} / \mathrm{L})\end{array}$} & \multirow[t]{2}{*}{ Treatment } \\
\hline & & & & & & & \\
\hline 1 & 5 & Female & 0.1 & 12 & $-/-$ & 3 & Operation \\
\hline 2 & 9 & Male & 20 & 8 & $-/-$ & 1 & Operation \\
\hline 3 & \multirow[t]{2}{*}{11} & \multirow[t]{2}{*}{ Male } & \multirow[t]{2}{*}{4} & \multirow[t]{2}{*}{2} & \multirow[t]{2}{*}{$+/-$} & \multirow[t]{2}{*}{1} & \multirow[t]{2}{*}{ Operation } \\
\hline 3 & & & & & & & \\
\hline 4 & 12 & Male & $1-\mathrm{Feb}$ & 4 & $+/+/+$ & 1-Jan & Conservative/Operation \\
\hline 5 & 8 & Female & 0.2 & 20 & $-/-$ & 9 & Conservative \\
\hline 6 & 3 & Male & 0.1 & 12 & $+/+$ & 15 & Conservative \\
\hline 7 & 13 & Female & 0.4 & 7 & $-/-$ & 11 & Operation \\
\hline 8 & 3 & Female & 3 & 12 & $+/-$ & 12 & Conservative \\
\hline 9 & 10 & Male & $0.3 / 6$ & 24 & $+/+/-$ & $17 / 0.5$ & Conservative/IA \\
\hline
\end{tabular}

+/- indicates that the imaging manifestations of appendicealfecalith are present in the first treatment, and noimaging manifestations of appendicealfecalith are present in the recurrence.

Table 2: Interval appendectomy.

\begin{tabular}{|c|c|c|c|c|c|}
\hline & Fecalith & Interval time (Mon) & Intraoperative situation & Pathology & Time of operation (Min) \\
\hline 1 & - & 2 & no obvious adhesion & chronic inflammation \\
\hline 2 & - & 6 & $\begin{array}{c}\text { No adhesion, the distal end of the appendix } \\
\text { self - amputation }\end{array}$ & chronic inflammation \\
\hline 3 & + & 4 & no obvious adhesion & chronic inflammation \\
\hline 4 & + & 4 & no obvious adhesion & chronic inflammation \\
\hline
\end{tabular}

Table 3: Recurrent appendectomy.

\begin{tabular}{|c|c|c|c|c|c|}
\hline & fecalith & Interval time (Mon) & Intraoperative situation & Pathology & Time of operation (Min) \\
\hline 1 & $\square$ & 0.1 & Obvious adhesion & Suppurative & 117 \\
\hline 2 & $\square$ & 20 & No adhesion, appendiceal congestion & Congestive & 47 \\
\hline 3 & $\square$ & 4 & $\begin{array}{l}\text { No adhesion, appearance congestive } \\
\text { swelling }\end{array}$ & Chronic & 53 \\
\hline 4 & $\square$ & 0.4 & $\begin{array}{c}\text { Obvious adhesion, greater omentum } \\
\text { wrapped }\end{array}$ & Gangrenous & 100 \\
\hline 5 & $\square$ & 1 & Obvious adhesion & Suppurative & 65 \\
\hline
\end{tabular}


Citation: Jingfeng B, Wenjun Z, Zhili D, Hailiang S, Yaqiang H (2020) Analysis of Follow-Up Results after Successful Conservative Treatment of Pediatric Appendiceal Abscess- A Single Institutional Retrospective Study. J Pediatr Congenit Dis 6(1): 102. DOI: https://doi.org/10.47275/2379-6707-102.

Table 4: Appendix fecalith and recurrence.

\begin{tabular}{|c|c|c|c|}
\hline & No. of cases & Male/ Female & Recurrence (recurrence rate) \\
\hline fecalith & 22 & $9 / 13$ & $5(22.7 \%)$ \\
\hline No fecalith & 26 & $12 / 14$ \\
\hline$\chi^{2}$ value & - & 0.11 & $4(15.4 \%)$ \\
\hline P value & - & $>0.05$ & 0.42 \\
\hline
\end{tabular}

\section{Discussion}

Acute appendicitis at the beginning of the onset of the disease if not timely and reasonable treatment, often lead to progress in the course of disease, in the appendix around the formation of inflammatory mass or appendiceal abscess. Children are more likely to develop appendiceal abscess due to their atypical clinical manifestations. At present, there are two main arguments about the treatment of appendiceal abscess: the first is a surgery or conservative treatment; secondly, whether it is necessary to perform planned interval appendectomy after conservative treatment. A prospectie study [1] concluded that early surgery is safe and feasible in children with appendiceal abscess. Some pediatric surgeons [2] have even made bold attempts to use laparoscopic one-stage surgery to treat pediatric appendiceal abscesses, providing a new treatment alternative.

But this has higher technical requirements for the surgeon, may not be widely adopted, and one stage surgery does have a higher complication rate [3]. A meta-analysis [4] found that the incidence of complications from conservative treatment of appendiceal abscess was significantly lower than that of primary surgery, so the first conservative treatment of appendiceal abscess was accepted by most doctors. In fact, the success rate of conservative treatment of appendiceal abscesses is currently high [5] due to the rational and standardized use of effective antibiotics and the assistance of imaging interventional techniques such as CT/ ultrasound localization or guided abscess puncture and drainage. In this study, 48 of the 55 cases of appendiceal abscess received the first conservative treatment successfully, with a success rate of $87 \%$. However, they were faced with the next treatment choice: the necessity of planned interval appendectomy and the time of interval. For adults, especially those over 40 years of age, most surgeons tend to planed interval appendectomy, which is more due to the increased rate of appendiceal-related tumor discovery [6]. In children, however, there has been no consensus on reoperation after conservative treatment of appendiceal abscesses, and both sides seem to have good reasons to support their views.

The reasons for advocating interval appendectomy are as follows: The first is the recurrence of successful conservative treatment of appendiceal abscess in children. A systematic review [7] reported that the recurrence rate of children with successful conservative treatment of appendiceal mass was nearly $20 \%$ and the presence of appendiceal fecalith significantly increased the recurrencerate. Ein et al [8] reported that the recurrence rate within 2 years even reached $43 \%$. The second is the pathology after interval appendectomy. In 2005, Erdogan [9] reported on the pathologic results of a group of children after interval appendectomy and found that nearly a quarter of the children had closed appendicitis, which was considered unlikely to recur. That is, pathologically, three out of four children treated conservatively had a risk of recurrence. In a recent study, Fouad [10] reported the pathologic findings of 149 children after interval appendectomy. Although no tumors were found, they suggested persistent active inflammation, meaning that conservative treatment could not achieve radical cure. Finally, it comes from the parents' social psychological pressure. A prospective, randomized study [11] found that the follow-up interval significantly increased parental stress and parenting stress. This is not groundless, the potential risk of recurrent appendicitis is likely to cause the stress and anxiety in parents, any fever, nausea, abdominal discomfort and other abnormal symptoms of the child may be considered relapse, thereby increasing the psychological burden on parents. In this study 4 cases of interval appendectomy were performed due to the urge of parents.

As for the interval of appendectomy, it is recommended that the symptoms disappear 6 months after the conservative treatment of appendiceal abscess, but the study [12] found that most of the recurrence of symptoms occurred in 6 months after conservative treatment. In this study, 89\% of recurrences occurred within 4 months after conservative treatment, so most of the patients underwent interval surgery 8-10 weeks later to prevent recurrence, some surgeons [13] attempted delayed appendectomy 1 month after successful conservation of an appendiceal abscess. During the operation, however, the appendix was found to adhere to the surrounding tissues. In this study, the interval of 4 patients with delayed operation was at least 10 weeks, no obvious adhesion was found during the operation, and the operation time was significantly shorter. Therefore, from the perspective of prevention of recurrence and surgery, we believe that 10 weeks is an ideal interval.

However, despite the above reasons, many scholars [14] do not advocate routine interval appendctomy after the first conservative treatment of children with appendiceal abscess. They concluded that the overall recurrence rate ( 20 percent) after conservative treatment of appendiceal abscesses was not high, and that the recurrence rate was about the same as the incidence of appendicitis in the general population and there was no recurrence within 3 months, with a lower recurrence rate later. During the follow-up period, in this study, the recurrence rate was $18.7 \%$, which was close to the above. In other words, prophylactic appendectomy did not benefit the remaining $80 \%$ of children. As a result, the child has to face the trauma of anesthesia and surgery, and possible postoperative complications. Further research [15] also found that the course of recurrent appendicitis was significantly shortened and the disease progression was milder. Our observational study also confirmed this view that the inflammatory indicators such as CRP in children with recurrent symptoms were significantly lower than in the first onset, and the recurrence of surgery did not significantly increase the difficulty of surgery or the incidence of complications. Based on the above analysis, therefore, conventional interval surgery after conservative treatment of appendiceal abscess in children is not necessary.

Even though most [16] believe the existence of the appendix fecalith can significantly increase the recurrence rate, interval operation is suggested for these patients. But the Japanese scholar of a prospective controlled study [17] found fecalith is not a predictor of recurrence, we also found no appendix fecalith existence has significant correlation with recurrence in this study. And we also noted the disappearance of appendiceal fecalith in many cases during the follow-up period, it is considered that the fecalith might be excreted through the intestinal tract or absorbed by degradation. 
Citation: Jingfeng B, Wenjun Z, Zhili D, Hailiang S, Yaqiang H (2020) Analysis of Follow-Up Results after Successful Conservative Treatment of Pediatric Appendiceal Abscess- A Single Institutional Retrospective Study. J Pediatr Congenit Dis 6(1): 102. DOI: https://doi.org/10.47275/2379-6707-102.

\section{Conclusion}

In conclusion, we suggest that children with successful conservative treatment of appendiceal abscess should be closely followed up for observation, without the need for routine interval appendectomy. Sometimes psychosocial status in parents should be fully considered to make rational and individual treatment decisions. Since our study was a single-institution retrospective study with a small sample size and no control group, it has certain limitations. A prospective controlled study with a larger sample is needed for further verification in the future.

\section{References}

1. Goh BKP, Chui CH, Yap TL, Low Y, Lama TK, et al. 2005. Is early laparoscopic appendectomy feasible in children with acute appendicitis presenting with an appendiceal mass? A prospective study. J Pediatr Surg 40(7):1134-1137.https://doi.org/10.1016/j.jpedsurg.2005.03.046

2. Ma LD, Li CL, Zhou FJ. 2013. Clinical analysis of 17 cases children periappendiceal abscess with therapeutic laparoscopy. J ClinPed Sur 12(3):191-193. https://doi.org/10.3969/j. issn.16716353.2013.03.008.

3. Zhang HW, JiaJ,Gao YX. 2012. Analysis of the treating experience of 61 children with appendicular abscess. J ClinPed Sur, 11(05): 335-337. https://doi.org/10.3969/j.issn.16716353.2012.05.005.

4. Simillis C, Symeonides P, Shorthouse AJ, Tekkis PP. 2010. A meta-analysis comparing conservative treatment versus acute appendectomy for complicated appendicitis (abscess orphlegmon). Surgery 147(6): 818-829.https://doi.org/10.1016/j.surg.2009.11.013

5. Fawley J, Gollin G. 2013. Expanded utilization of non-operative management for complicated appendicitis in children. Langenbeck's Arch Surg 398(3): 463-466.https://doi.org/10.1007/ s00423-012-1042-5

6. Wright GP, Mater ME, Carroll JT, Choy JS, Chung MH. 2015. Is there truly an oncologic indication for interval appendectomy? Am J Surg 209(3): 442-446.https://doi.org/10.1016/j amjsurg.2014.09.020

7. Hall NJ, Jones CE, Eaton S, Stanton MP, Burge DM. 2011. Is interval appendicectomy justified after successful non-operative treatment of an appendix mass in children? A systematicreview. J Pediatr Surg 46(4): 767-771.https://doi.org/10.1016/j.jpedsurg.2011.01.019

8. Ein SH, Langer JC, Daneman A. 2005. Nonoperative management of pediatric ruptured appendix with inflammatory mass or abscess: presence of an appendicolith predictsrecurrentappendicitis. J pediatr Surg 40(10):1612-1615.https://doi.org/10.1016/j.jpedsurg.2005.06.001

9. Erdogan D, Karaman I, Narci A, Karaman A, Cavuşoğlu YH, et al. 2005. Comparison of two methods for the management ofappendicular mass in children. Pediatr Surg Int 21(2):81-83. https://doi.org/10.1007/s00383-004-1334-0

10. Fouad D, Kauffman JD, Chandler NM. 2020. Pathology findings following interval appendectomy: should it stay or go? J Pediatr Surg 55(4): 737-741.https://oi.org/10.1016/j. jpedsurg.2019.05.001

11. Schurman JV, Cushing CC, Garey CL, Laituri CA, St Peter SD, et al. 2011. Quality of life assessment between laparoscopic appendectomy at presentation and interval appendectomyfor perforated appendicitis with abscess:analysis of a prospective randomized trial. J Pediatr Surg 46 (6): 1121-1125.https://doi.org/10.1016/j.jpedsurg.2011.03.038

12. Tekin A, Kurtoğlu HC, Can I, Oztan S, et al. 2008. Routine interval appendectomy is unnecessary after conservative treatment of appendiceal mass. Colorectal Dis 10(5): 465-468. https://doi.org/10.1111/j.1463-1318.2007.01377.x

13. Wei DC, Qi SQ, Huang H. 2013. Discussion on delayed appendectomy after successful conservation of appendiceal abscess in children. J ClinPed Sur 12(4): 336-338. https://doi. org/10.3969/j.issn.1671-6353.2013.04.025.

14. Puapong D, Lee SL, Haigh PI, Kaminski A, Liu I-LA.2007. Routine interval appendectomy in children is not indicated. J Pediatr Surg 42(9): 1500-1503.https://doi.org/10.1016/j. jpedsurg.2007.04.011

15. Al-Qahtani H, Alam MK, Al-Akeely MH, Al-Salamah SM. 2010. Routine or selective interval appendectomy for non-surgically treated appendiceal mass. Journal of Taibah UniversityMedical Sciences 5(2):105-109.https://doi.org/10.1016/s1658-3612(10)70139-6

16. Zhang HL, Bai YZ, Zhou X, Wang WL. 2013. Nonoperative management of appendiceal phlegmon or abscess with an appendicolith in children. J Gastrointest Surg 17(4): 766-770. https://doi.org/10.1007/s11605-013-2143-3

17. Tanaka Y, Uchida H, Kawashima H, Fujiogi M, Suzuki K, et al. 2016. More than one-third of successfully nonoperativelytreated patients with complicated appendicitis experiencedrecurrent appendicitis: Is interval appendectomy necessary? J Pediatr Surg 51(12): 1957-1961.https://doi.org/10.1016/j.jpedsurg.2016.09.017 